\title{
Transient high thyroid stimulating hormone and hypothyroidism incidence during follow up of subclinical hypothyroidism
}

\author{
Munir Abu-Helalah ${ }^{1,2}$, Hussam Ahmad AlshraideH ${ }^{3,4}$, Sameeh Abdulkareem Al-Sarayreh ${ }^{5}$, \\ AbdelFattah AL-HADER ${ }^{6}$
}

${ }^{1}$ Department of Public Health, Faculty of Medicine, Mutah University, Karak, Jordan; ${ }^{2}$ Department of Public Health, Faculty of Medicine, Alfaisal University, Riyadh, KSA; ${ }^{3}$ Industrial Engineering Department, Jordan University of Science and Technology, Irbid, Jordan; ${ }^{4}$ Industrial Engineering Department, American University of Sharjah, Sharjah, UAE; ${ }^{5}$ Department of Biochemistry and Molecular Biology, Faculty of Medicine, Mutah University, Karak, Jordan; ${ }^{6}$ Department of Physiology, Faculty of Medicine, 42 Jordan University of Science and Technology, Irbid, Jordan E-mail: haalshraideh@just.edu.jo

Objectives. Given the high prevalence of subclinical hypothyroidism ( $\mathrm{SCH})$, defined as high thyroid stimulating hormone (TSH) and normal free thyroxine (FT4), and uncertainty on treatment, one of the major challenges in clinical practice is whether to initiate the treatment for $\mathrm{SCH}$ or to keep the patients under surveillance. There is no published study that has identified predictors of short-term changes in thyroid status amongst patients with mild elevation of TSH (4.5-10 mIU/L).

Subjects and Results. A cohort study was conducted on patients with SCH detected through a general population screening program, who were followed for six months. This project identified factors predicting progression to hypothyroid status, persistent $\mathrm{SCH}$ and transient cases. A total of 656 participants joined the study (431 controls and 225 were patients with SCH). A part of participants (12.2\%) developed biochemical hypothyroidism during the follow-up, while $73.8 \%$ of the subjects became euthyroid and the remained ones (13.4\%) stayed in the SCH status. The incidence of overt hypothyroidism for participants with TSH above $6.9 \mathrm{mIU} / \mathrm{L}$ was $36.7 \%$, with incidence of $42.3 \%$ for females. Anti-thyroid peroxidase antibodies (TPO) positivity is an important predictor of development of hypothyroidism; however, it could be also positive due to transient thyroiditis.

Conclusions. It can be concluded that females with TSH above $6.9 \mathrm{mIU} / \mathrm{L}$, particularly those with free triiodothyronine (FT3) and FT4 in the lower half of the reference range, are more likely to develop biochemical hypothyroidism. Therefore, it is recommended to give them a trial of levothyroxine replacement. It is also recommended to repeat TSH after six months for male subjects and participants with baseline TSH equal or less than $6.9 \mathrm{mIU} / \mathrm{L}$.

Key words: subclinical, hypothyroidism, transient, predictors, euthyroid, cohort

Adult primary hypothyroidism is widely considered to be a common, but difficult to diagnose in its milder forms because the typical symptoms, such as lethargy, tiredness, weight gain, memory impairment, and depression, are non-specific and experienced by many people (Jameson and Weetman 2001; Wass and Stewart 2011).
The reported prevalence of biochemical primary hypothyroidism, defined as high thyroid stimulating hormone (TSH) and low free thyroxine (FT4), is between $1 \%$ and $2 \%$ (Canaris et al. 2000; Vanderpump and Tunbridge 2002; Wilson et al. 2006), while the reported prevalence of subclinical hypothyroidism $(\mathrm{SCH})$, defined as high TSH and normal FT4, ranges

Corresponding author: Hussam Alshraideh, PhD., Associate Professor of Statistics and Analytics, Industrial Engineering Department, Jordan University of Science and Technology, 112 King Hussain Street, Postal Code: 22110, Irbid, Jordan;

Fax: 962-02-7201000; phone: 00971529216977, e-mail: haalshraideh@just.edu.jo. halshraideh@aus.edu 
between 2.9\% and 10\% (Canaris et al. 2000; Vanderpump and Tunbridge 2002; Wilson et al. 2006). At the SCH stage of the disease, the patients might have few symptoms or they are asymptomatic, but feel the difference in some symptoms after introduction of replacement thyroxine treatment (Vanderpump and Tunbridge 2002).

Given the high prevalence of $\mathrm{SCH}$ and uncertainty on treatment, one of the major challenges to family medicine doctors and internists is whether to initiate treatment for SCH or to keep the patients under surveillance (Khandelwal and Tandon 2012; Redford and Vaidya 2017). Symptoms, as discussed above, are insidious and most are non-specific (Jameson and Weetman 2001; Wass and Stewart 2011). Trial of treatment could be helpful in prevention of progression of the disease and symptomatic relief (Jonklaas et al. 2014). One of the current challenges in medical practice is identification of $\mathrm{SCH}$ patients, who would progress to biochemical hypothyroidism, and would, therefore, require early initiation of thyroxine replacement (Premawardhana and Lazarus 2006). High level of TSH (>10 mIU/L), presence of antithyroid antibodies, cardiovascular risk factors, and other co-morbidities have predicted initiation of therapy in clinical practice (Cojic and Cvejanov-Kezunovic 2017).

Repeat TSH after six months shows that the patients have either persistent high TSH, progression to biochemical primary hypothyroidism or a normal TSH (Abu-Helalah et al. 2010). Those who became euthyroid most probably experienced an episode of silent thyroiditis with a transient hypothyroid phase (Dimos et al. 2010; Ohsako et al. 1995). Progression to overt hypothyroidism, occurs at different rates ranging from 5 to $17 \%$ (Jonklaas et al. 2014; Huber et al. 2002; Tunbridge et al. 1981; Vanderpump et al. 1995). In selected cases (e.g., elderly patients with high titres of antithyroid antibodies), the risk of progression to overt disease may be closer to $20 \%$ per year. Consideration of these possible outcomes affects the decision about whether to treat or to observe without treatment (Cojic and Cvejanov-Kezunovic 2017; Abu-Helalah et al. 2010; Dimos et al. 2010; Ohsako et al. 1995; Huber et al. 2002; Tunbridge et al. 1981; Vanderpump et al. 1995; Garber et al. 2012).

A randomized double-blind cross-over clinical trial on SCH patients identified through population based general screening showed that $27 \%$ of patients with repeat TSH after 3 to 6 months after initial screening will have TSH higher than $4.5 \mathrm{mIU} / \mathrm{L}$, while $73 \%$ of them will have their TSH below this figure. Results have shown that the former group would benefit from treatment through improvement in selected symptoms, their own rating and reduction in their LDL cholesterol (Abu-Helalah et al. 2010).

A recent systematic review has recommended that diagnosis of SCH should not lead to initiation of therapy particularly in cases with mild elevation. This systematic review also recommended ruling out transient SCH (i.e., not persistent for $>3-6$ months). This means that there are patients with true SCH who could benefit symptomatically from treatment, but will be kept without treatment for three to six months (Abreu et al. 2017).

The question on determination of the group with mild elevation of TSH (4.5-10 mIU/L), who is more likely to develop biochemical hypothyroidism permanently, is still unresolved. There is no published study that has identified predictors of short-term changes in thyroid status. Most studies are based on long-term changes in TSH without investigating the early phases of the disease process (Cojic and Cvejanov-Kezunovic 2017; Abu-Helalah et al. 2010; Dimos et al. 2010; Ohsako et al. 1995; Huber et al. 2002; Tunbridge et al. 1981; Vanderpump et al. 1995; Garber et al. 2012).

We conducted a cohort study on patients identified with SCH detected through a general population screening program. This project identified factors predicting progression to hypothyroid status, persistent $\mathrm{SCH}$, and transient cases. We hope that our findings will support initiation of treatment for $\mathrm{SCH}$ according to predetermined criteria, rather than keeping all patients off treatment and waiting for three to six months for initiation of therapy.

This study aims at identifying factors that predict progression to hypothyroid status, persistent $\mathrm{SCH}$, and transient cases to help in developing treatment protocols.

\section{Subjects and Methods}

Subjects. This cohort study is based on follow up of SCH patients detected through general population screening study. An Institutional Review Board (IRB) approval was obtained from the Ministry of Health Central Ethical Review Committee and from the Ethical Review Committee at the Faculty of Medicine, Mutah University, Karak, Jordanian agreement with the Helsinki Declaration of 1975.

Each subject was informed about the study and duration of follow-up of 6 months. Those who agreed to take part were consented for taking part in the study. Blood samples were collected from them on monthly basis. All participants received a letter of 
their biochemical tests and the outcomes of their follow up. Those who develops biochemical hypothyroidism during the follow up were informed about this outcome and a letter for the healthcare provider along with the biochemical tests results were given to the participants to share with their physicians.

Inclusion criteria. Participants in Jordan National Thyroid Epidemiology Study, aged 18 to 79, who were detected with subclinical hypothyroidism, were invited to take part in this cohort study, described by Abu-Helalah et al. (2019). This was done within few days of the initial test. A soon as the results of the screening test, within 5-7 days of initial screening, patients were invited to take place. The levels of TSH and FT4 were not repeated in the inclusion visit. The second test was conducted at one month from the initial screening test. Also, matched euthyroid controls for age, gender, and location, were recruited from the same project. Control group were identified from participants in the above-mentioned Jordan National Thyroid Epidemiology Project and who were euthyroid; screen negative.

Exclusion criteria. Patients with the following conditions were not invited to join the study: People who have difficulties in communication. People not permanently residing in the study areas. People who have a medical condition or are taking drugs that affect TSH secretion or thyroid hormone secretion, absorption, transport, or metabolism, as described by Abu-Helalah et al. (2019).

The purpose of their inclusion is to compare baseline results with study participants and to compare the prevalence of symptoms suggestive of hypothyroidism. These controls were screen negative subjects in the Jordan National Thyroid Epidemiology Project, source of subjects for this study. Methodology and results of the above project are described by $\mathrm{Abu}$ Helalah et al. (2019). Patients with SCH secondary to underlying conditions such as surgery, radiation therapy, or treatments, pregnant women, or on treatments that would affect any of the study outcomes were excluded from the study.

Definitions:

1. SCH: high TSH, normal FT4 and free triiodothyronine (FT3);

2. Overt hypothyroidism: high TSH, low FT4 and/or FT3;

3. Subclinical hyperthyroidism: low TSH, normal FT4 and FT3;

4. Overt hyperthyroidism: low TSH, high FT4 and/or FT3.

The incidence of biochemical hypothyroidism amongst patients with $\mathrm{SCH}$ detected through from general population screening was calculated. Moreover, predictors of deterioration in disease status for patients with SCH were identified. Finally, predictors of normalization of TSH and persistence of SCH status were also evaluated.

Biochemistry. Serum TSH, FT4, and FT3 were measured by chemiluminescent immunoassays (Advia Centaur; Bayer Diagnostics, Newbury, United Kingdom). Serum TSH had a laboratory reference range of $0.4-4.5 \mathrm{mIU} / \mathrm{L}$ with an interassay coefficient of variation of $4.4-10.9 \%$ over the range of $0.41-24.5 \mathrm{mIU} / \mathrm{L}$. The assay was calibrated against the second International Reference Preparation 80/558. The lower limit of reporting for the TSH assay was $0.1 \mathrm{mIU} / \mathrm{L}$ and the manufacturer's quoted mean functional sensitivity was $0.019 \mathrm{mIU} / \mathrm{L}$. The laboratory reference range for FT4 was 9.0-20.0 pmol/L with an interassay coefficient of variation of $8.2-9.8 \%$ over the range of $8.2-54.9 \mathrm{pmol} / \mathrm{L}$. Serum TSH and FT4 concentrations were determined in all; in those with serum TSH below normal, serum FT3 (reference range 3.5-6.5 pmol/L, interassay coefficient of variation of $4.2-6.9 \%$ over the range $4.0-16.0 \mathrm{pmol} / \mathrm{L}$ ) was also measured (Lee and Lee 2014). Anti-thyroid peroxidase antibodies (TPO) antibodies were measured by the electrochemiluminescence immunoassay (ECLIA) method (Roche) and the reference range in humans is between 0 and $34 \mathrm{IU} / \mathrm{mL}$

Sample size calculation. This work is a part of a bigger project that aimed at estimating the prevalence of hypothyroidism and hyperthyroidism in Jordan described in details by Abu-Helalah et al. (2019). Out of the 7,085 participants in the national crosssectional study, a total of 383 patients were identified with $\mathrm{SCH}$ and were asked to participate in the follow up study. Of those patients, 225 consented to participate in this follow up study and 53 of them were lost during the follow up period. As for control patients, a sample of size 385 is sufficient at a $95 \%$ significance level and 5\% error margin (Kish 1965).

Statistical analysis. The primary objective of this study is to identify predictors of biochemical hypothyroidism among SCH patients. Descriptive statistics including means, standard deviations and proportions will be reported. Summaries will be provided for both subclinical hypothyroid subjects and control participants. Logistic regression techniques will be used to identify significant predictors of biochemical hypothyroidism development. Two cases for TSH, FT4 and FT3 test results will be evaluated for their effects on biochemical hypothyroidism development. In the first case, continuous values for TSH, FT4 and FT3 test results will be assumed. In the second case, 
test results will be categorized into pre-specified set of ranges. Two levels for the TSH test results will be used $\leq 6.9 \mathrm{mIU} / \mathrm{L}$ and $>6.9 \mathrm{mIU} / \mathrm{L}$. The FT4 and FT3 levels will be categorized in two scenarios. In the first scenario, FT4 is assumed to have three categories $\leq 13.67,13.67$ to 15.18 , and $>15.18 \mathrm{pmol} / \mathrm{L}$; and FT3 is assumed to have three categories $\leq 3.20,3.20$ to 3.38 , and $>3.38 \mathrm{pmol} / \mathrm{L}$. In the second scenario, FT4 and FT3 serum levels will be split into upper and lower halves: FT4 $\leq 14.44$ or $>14.44 \mathrm{pmol} / \mathrm{L}$, and FT3 $\leq 3.79$ or $>3.79 \mathrm{pmol} / \mathrm{L}$. Throughout the performed analysis, a $95 \%$ confidence level will be assumed.

\section{Results}

A total of 656 participants joined the study. The control group was comprised of 431 individuals, while the remaining 225 were patients with SCH detected through general population screening program(s) and consented to participate in the follow-up. The participation rate amongst eligible patients was $58.7 \%$ of initially invited 1118 patients, who were identified with $\mathrm{SCH}$ in the national epidemiology study with TSH between 4.5 and 10 and normal FT4 and FT3 (Abu-Helalah et al. 2019). Most of decliners (458 out of 462) reported that they could not join due to personal commitments, except four subjects who wanted to start treatment. Baseline biochemical tests and demographics had no statistically different from participants.

At baseline, there was no statistically significant difference between these two groups in the mean age or gender distribution. The mean age of the control group was $42 \pm 13.7$ years and the mean age for the follow-up group was $43 \pm 14$. 6 years. Both groups were also matched for geographical location.

As shown in Table 1, there was a statistically significant difference between controls and patients with $\mathrm{SCH}$ in the biochemical parameters with higher TSH, more positive rate for TPO, C-reactive protein (CRP) and erythrocyte sedimentation rate (ESR), and lower FT4 in the SCH compared with euthyroid controls.

At the end of follow-up, SCH were split into three groups based on their biochemical findings: remained in the SCH status; became euthyroid; developed biochemical hypothyroidism. Not unexpectedly, further analysis of baseline tests revealed that subjects who developed hypothyroidism had higher TSH, lower FT4 and FT3 and more often positive for TPO, CRP and ESR when compared with participants who stayed as $\mathrm{SCH}$ or became euthyroid, as shown in Table 2. Chi-Square analysis showed

Table 1

Baseline and end of follow-up biochemical tests assessment

\begin{tabular}{|c|c|c|c|c|c|c|}
\hline & \multirow[t]{2}{*}{ Test } & \multicolumn{2}{|c|}{$\begin{array}{l}\text { Control } \\
(n=431)\end{array}$} & \multicolumn{2}{|c|}{$\begin{array}{c}\text { Subclinical hypothyroid patients } \\
(\mathrm{n}=225)\end{array}$} & \multirow[t]{2}{*}{ p-value } \\
\hline & & Mean & SD & Mean & SD & \\
\hline \multirow[t]{3}{*}{ Baseline } & TSH (mIU/L) & 2.23 & 1.78 & 5.90 & 1.24 & 0.000 \\
\hline & FT4 (pmol/L) & 15.23 & 1.98 & 14.44 & 2.56 & 0.000 \\
\hline & FT3 (pmol/L) & 3.29 & 1.09 & 3.38 & 0.87 & 0.292 \\
\hline \multirow[t]{5}{*}{ Baseline } & Test & \multicolumn{2}{|c|}{$\begin{array}{c}\text { Control } \\
\text { (\% of positive cases) }\end{array}$} & \multicolumn{2}{|c|}{$\begin{array}{l}\text { Subclinical hypothyroid patients } \\
\text { (\% of positive cases) }\end{array}$} & p-value \\
\hline & TPO & \multicolumn{2}{|c|}{10.3} & \multicolumn{2}{|c|}{46.0} & 0.000 \\
\hline & CRP & \multicolumn{2}{|c|}{24.9} & \multicolumn{2}{|c|}{57.1} & 0.000 \\
\hline & TSH receptors & \multicolumn{2}{|c|}{3.6} & \multicolumn{2}{|c|}{3.7} & 1.000 \\
\hline & ESR & \multicolumn{2}{|c|}{35.6} & \multicolumn{2}{|c|}{60.9} & 0.000 \\
\hline \multirow{5}{*}{$\begin{array}{l}\text { End of } \\
\text { follow-up }\end{array}$} & \multicolumn{5}{|c|}{ Proportion of follow-up patients (\%) } & \\
\hline & Group & Female & Male & Total & $\begin{array}{l}\text { TSH }(\mathrm{mIU} / \mathrm{L}) \\
\text { Mean } \pm \text { SD }\end{array}$ & $\begin{array}{l}\text { FT4 }(\mathrm{pmol} / \mathrm{L}) \\
\text { Mean } \pm \text { SD }\end{array}$ \\
\hline & Stayed as $\mathrm{SCH}$ & 14.5 & 11.1 & 13.4 & $6.0 \pm 1.2$ & $14.9 \pm 2.1$ \\
\hline & Biochemical HPT & 16.1 & 0.0 & 12.2 & $9.2 \pm 3.7$ & $11.5 \pm 1.9$ \\
\hline & Became euthyroid & 69.4 & 88.9 & 73.8 & $0.8 \pm 15.1$ & $15.1 \pm 2.0$ \\
\hline
\end{tabular}

Abbreviation: CRP - C-reactive protein; ESR - erythrocyte sedimentation rate; FT3 - free triiodothyronine; FT4 - free thyroxine; HPT - hypothyroidism; SCH - subclinical hypothyroidism; TPO - anti-thyroid peroxidase antibodies; TSH - thyroid stimulating hormone. 
Table 2

Biochemical tests at baseline according to status at the end of the follow-up

\begin{tabular}{|c|c|c|c|c|c|c|c|c|c|}
\hline Parameter & Status & Min & Q1 & Mean & SD & Median & Q3 & Max & p-value \\
\hline \multirow{3}{*}{$\begin{array}{l}\text { TSH } \\
(\mathrm{mIU} / \mathrm{L})\end{array}$} & Stayed as $\mathrm{SCH}$ & 4.60 & 5.11 & 6.32 & 1.49 & 6.09 & 7.34 & 9.69 & \multirow[t]{3}{*}{0.000} \\
\hline & Biochemical HPT & 5.03 & 5.79 & 6.91 & 1.43 & 6.90 & 8.20 & 9.49 & \\
\hline & Became euthyroid & 4.52 & 4.85 & 5.65 & 1.05 & 5.39 & 6.18 & 9.37 & \\
\hline \multirow{3}{*}{$\begin{array}{l}\text { FT4 } \\
(\mathrm{pmol} / \mathrm{L})\end{array}$} & Stayed as $\mathrm{SCH}$ & 10.23 & 12.71 & 14.06 & 2.03 & 14.49 & 15.26 & 18.16 & \multirow[t]{3}{*}{0.001} \\
\hline & Biochemical HPT & 8.06 & 10.86 & 12.75 & 2.34 & 12.61 & 14.50 & 16.93 & \\
\hline & Became euthyroid & 2.39 & 13.49 & 14.79 & 2.57 & 14.57 & 16.26 & 21.50 & \\
\hline \multirow{3}{*}{$\begin{array}{l}\text { FT3 } \\
(\mathrm{pmol} / \mathrm{L})\end{array}$} & Stayed as $\mathrm{SCH}$ & 2.47 & 3.10 & 3.24 & 0.25 & 3.30 & 3.38 & 3.76 & \multirow[t]{3}{*}{0.832} \\
\hline & Biochemical HPT & 2.16 & 2.95 & 3.17 & 0.38 & 3.38 & 3.38 & 3.80 & \\
\hline & Became euthyroid & 2.29 & 3.14 & 3.44 & 0.99 & 3.38 & 3.52 & 12.90 & \\
\hline
\end{tabular}

Abbreviations: FT4 - free thyroxine; FT3 - free triiodothyronine; HPT - hypothyroidism; SCH - subclinical hypothyroidism; SD standard deviation; TSH - thyroid stimulating hormone.

Table 3

Chi-squared analysis for the association between biochemical test results and end of follow-up status

\begin{tabular}{|c|c|c|c|c|}
\hline Parameter & Category (\%) & $\begin{array}{c}\text { Stayed } \\
\text { as SCH } \\
(\mathrm{n}=23)\end{array}$ & $\begin{array}{l}\text { Biochemical } \\
\text { HPT }(n=21)\end{array}$ & $\begin{array}{c}\text { Became } \\
\text { euthyroid } \\
(n=127)\end{array}$ \\
\hline \multirow[t]{3}{*}{ TPO } & Negative & 54.5 & 20.0 & 59.7 \\
\hline & Positive & 45.5 & 80.0 & 40.3 \\
\hline & p-value & & 0.004 & \\
\hline \multirow[t]{3}{*}{ CRP } & Negative & 45.5 & 30.0 & 44.5 \\
\hline & Positive & 54.5 & 70.0 & 55.5 \\
\hline & $\mathrm{p}$-value & & 0.461 & \\
\hline \multirow[t]{3}{*}{ ESR } & Negative & 36.4 & 15.0 & 43.7 \\
\hline & Positive & 63.6 & 85.0 & 56.3 \\
\hline & p-value & & 0.050 & \\
\hline \multirow{3}{*}{$\begin{array}{l}\text { TSH } \\
\text { receptor }\end{array}$} & Negative & 100.0 & 100.0 & 95.0 \\
\hline & Positive & 0.0 & 0.0 & 5.0 \\
\hline & $\mathrm{p}$-value & & 0.493 & \\
\hline \multirow{3}{*}{$\begin{array}{l}\text { TSH } \\
(\mathrm{mIU} / \mathrm{L})\end{array}$} & $\leq 6.9$ & 68.2 & 50.0 & 89.9 \\
\hline & $>6.9$ & 31.8 & 50.00 & 10.1 \\
\hline & p-value & & 0.000 & \\
\hline \multirow{3}{*}{$\begin{array}{l}\text { FT4 } \\
(\mathrm{pmol} / \mathrm{L})\end{array}$} & $\leq 14.44$ & 50.0 & 75.0 & 47.9 \\
\hline & $>14.44$ & 50.0 & 25.0 & 52.1 \\
\hline & $\mathrm{p}$-value & 0.080 & & \\
\hline \multirow{3}{*}{$\begin{array}{l}\text { FT3 } \\
(\mathrm{pmol} / \mathrm{L})\end{array}$} & $\leq 3.79$ & 100.0 & 95.0 & 87.4 \\
\hline & $>3.79$ & 0.0 & 5.0 & 12.6 \\
\hline & $\mathrm{p}$-value & & 0.168 & \\
\hline
\end{tabular}

Abbreviation: CRP - C-reactive protein; ESR - erythrocyte sedimentation rate; FT3 - free triiodothyronine; FT4 free thyroxine; HPT - hypothyroidism; SCH - subclinical hypothyroidism; TPO - anti-thyroid peroxidase antibodies; TSH - thyroid stimulating hormone. statistically significant differences between the three groups in the TPO positivity, as shown in Table 3.

Follow-up results of final thyroid status of $\mathrm{SCH}$ patients showed that $12.2 \%$ of participants developed biochemical hypothyroidism during the followup period of six months while $73.8 \%$ of the subjects became euthyroid and the remaining $13.4 \%$ stayed in the SCH status. Interestingly, 0.58\% (1 subject) of the participants with SCH developed hyperthyroidism during the follow up.

A multinomial logistic regression model was built to predict patients who would develop biochemical hypothyroidism or had their TSH within the target reference range when compared with those who remaining within the SCH category. Model regression coefficients are included.

Regression analysis was conducted assuming two scenarios for TSH, FT4 and FT3 variables. In the first scenario, all three variables were assumed to follow a continuous scale (Table 1), while categorization into different levels was assumed in the second scenario (Tables 2 and 3). The latter scenario was done in order to have feasible recommendations for clinical practice utilization of the outcomes.

Considering TSH, FT4 and FT3 as continuous variables, regression analysis (Table 4 ) showed that TSH and older age are associated with higher probability of developing biochemical hypothyroidism compared to remaining as is in the SCH status. Male participants, ex-users of oral contraceptives, those with higher FT4, higher FT3 were less likely to develop biochemical hypothyroidism. Regarding having TSH returning to normal "reference range" those with higher FT3 and non- or ex-users of oral contraceptives were more likely to have their TSH 
Table 4

Predictors of end of follow-up status assuming a continuous scale for TSH, FT4 and FT3

\begin{tabular}{|c|c|c|c|c|}
\hline & \multicolumn{2}{|c|}{ Biochemical HPT } & \multicolumn{2}{|c|}{ Became euthyroid } \\
\hline & Coefficient & p-value & Coefficient & p-value \\
\hline (Intercept) & 6.7 & 0.156 & 4.9 & 0.163 \\
\hline $\begin{array}{l}\text { Reached menopause } \\
\text { (women): Yes }\end{array}$ & -3.3 & 0.011 & -1.2 & 0.168 \\
\hline $\begin{array}{l}\text { Oral contraceptive } \\
\text { pills (women): } \\
\text { Ex-user }\end{array}$ & -1.4 & 0.356 & 0.2 & 0.891 \\
\hline $\begin{array}{l}\text { Oral contraceptive } \\
\text { pills (women): No }\end{array}$ & 0.0 & 0.986 & 2.0 & 0.137 \\
\hline Gender: Male & -11.7 & 0.000 & -0.2 & 0.826 \\
\hline Age & 0.05 & 0.213 & -0.03 & 0.270 \\
\hline TSH & 0.2 & 0.552 & -1.0 & 0.000 \\
\hline FT4 & -0.4 & 0.019 & -0.1 & 0.360 \\
\hline FT3 & -1.0 & 0.360 & 1.2 & 0.113 \\
\hline
\end{tabular}

Abbreviations: FT4 - free thyroxine; FT3 - free

triiodothyronine; HPT - hypothyroidism; TSH - thyroid stimulating hormone

Table 5

Predictors of end of follow-up status assuming a categorical scales for TSH $(\leq 6.9$ or $>6.9 \mathrm{mIU} / \mathrm{L})$, FT4 $(\leq 14.44$ or $>14.44 \mathrm{pmol} / \mathrm{L})$ and FT3 $(\leq 3.79$ or $>3.79 \mathrm{pmol} / \mathrm{L})$

\begin{tabular}{lcccc}
\hline & \multicolumn{2}{c}{ Biochemical HPT } & \multicolumn{2}{c}{ Became euthyroid } \\
\cline { 2 - 5 } & Coefficient & p-value & Coefficient & p-value \\
\hline (Intercept) & -6.5 & 0.000 & 16.1 & 0.000 \\
$\begin{array}{l}\text { Reached menopause } \\
\text { (women): Yes }\end{array}$ & -2.6 & 0.031 & -0.9 & 0.267 \\
$\begin{array}{l}\text { Hormonal } \\
\text { replacement therapy } \\
\text { (women): No }\end{array}$ & 4.8 & 0.000 & -14.4 & 0.000 \\
$\begin{array}{l}\text { Oral contraceptive } \\
\text { pills (women): }\end{array}$ & -0.8 & 0.567 & 0.3 & 0.842 \\
Ex-user & & & & \\
$\begin{array}{l}\text { Oral contraceptive } \\
\text { pills (women): No }\end{array}$ & 0.3 & 0.839 & 2.2 & 0.105 \\
Gender: Male & -17.0 & 0.000 & -0.3 & 0.687 \\
Age & 0.04 & 0.267 & -0.03 & 0.298 \\
TPO: Positive & 1.4 & 0.062 & 0.1 & 0.810 \\
TSH >6.9 mIU/L & 0.03 & 0.964 & -2.5 & 0.000 \\
\hline Abbreviatons: FT3 free tritod & & & & \\
\hline
\end{tabular}

Abbreviations: FT3 - free triiodothyronine; FT4 - free thyroxine; HPT - hypothyroidism; TPO - anti-thyroid peroxidase antibodies; TSH - thyroid stimulating hormone.

returning to reference range during the follow-up. On the other hand, those with higher TSH and postmenopausal women are less likely to return to normal when compared with stay as it is status.
We repeated regression analysis after categorizing the TSH, FT4 and FT3. In Table 5, FT4 and FT3 values, which were within the reference range, were split into two halves, while in Table 5, they were split into three categories. Obtained categories for each case are shown in the caption of the corresponding table. In Table 5, TPO positive status, age, non-users of hormone replacement therapies, and having a baseline TSH more than $6.9 \mathrm{mIU} / \mathrm{L}$ are associated with higher probability of developing biochemical hypothyroidism compared with staying the subclinical hypothyroid status. On the other hand, male gender, women who reached menopause, ex-users of oral contraceptives are associated with lower probability of developing biochemical hypothyroidism when compared with staying the SCH status. The incidence of overt hypothyroidism for participants with TSH above $6.9 \mathrm{mIU} / \mathrm{L}$ was $36.7 \%$. For female participants, incidence of overt hypothyroidism was $16.1 \%$, while it was $42.3 \%$ for female participants with TSH at baseline level above $6.9 \mathrm{mIU} / \mathrm{L}$.

Non- or ex-users of oral contraceptives were statistically significant predictors of having TSH returning to reference "normal" range, when compared with staying within the subclinical hypothyroid category. One the other hand, TSH higher than $6.9 \mathrm{mIU} / \mathrm{L}$, non-users of hormonal therapies and higher age were unlikely to have their TSH returning to reference "normal" range.

Finally, Table 6 shows that TSH higher than 6.9 $\mathrm{mIU} / \mathrm{L}$ and positive TPO were statistically significant predictors of development of biochemical hypothyroidism when compared with staying within the subclinical hypothyroid status. Male gender, postmenopausal women, FT3>3.2 pmol/L, and ex-users of oral contraceptives were unlikely to develop biochemical hypothyroidism and more like to stay in the subclinical status. Patients with FT3 more than $3.2 \mathrm{pmol} / \mathrm{L}$, non- or ex-users of oral contraceptives, TPO positive were more likely to have their TSH returning to the reference range. On the other hand, post-menopausal women, male participants, those with TSH higher than $6.9 \mathrm{mIU} / \mathrm{L}$, and those at older age were less likely to have their TSH returning to reference range when compared with staying in the subclinical hypothyroid status.

\section{Discussion}

The question of whether or not to initiate thyroxine replacement upon diagnosis for the highly prevalent $\mathrm{SCH}$ could be answered to a large extent based on results of our study. We have provided evidence 
Table 6

Predictors of end of follow-up status assuming a categorical scales for TSH $(<=6.9$ or $>6.9 \mathrm{mIU} / \mathrm{L}), \mathrm{FT} 4(\leq 13.67$, $13.67-15.18,>15.18 \mathrm{pmol} / \mathrm{L})$ and FT3 $(\leq 3.20,3.20-3.38,>3.38$ $\mathrm{pmol} / \mathrm{L})$

\begin{tabular}{lcccc}
\hline & \multicolumn{2}{c}{ Biochemical HPT } & \multicolumn{2}{c}{ Became euthyroid } \\
\cline { 2 - 5 } & Coefficient & p-value & Coefficient & p-value \\
\hline (Intercept) & -1.4 & 0.454 & 0.9 & 0.554 \\
$\begin{array}{l}\text { Reached } \\
\text { menopause } \\
\text { (women): Yes }\end{array}$ & -2.5 & 0.042 & -0.6 & 0.463 \\
Oral contraceptive & -1.0 & 0.522 & 0.01 & 0.997 \\
pills (women): & & & & \\
Ex-user & & & & \\
$\begin{array}{l}\text { Oral contraceptive } \\
\text { pills (women): No }\end{array}$ & 0.0 & 0.999 & 2.1 & 0.132 \\
Gender: Male & -17.1 & 0.000 & -0.2 & 0.842 \\
Age & 0.04 & 0.258 & -0.02 & 0.329 \\
TPO: Positive & 1.7 & 0.059 & 0.1 & 0.900 \\
TSH > 6.9 mIU/L & 0.03 & 0.965 & -2.6 & 0.000 \\
FT3 > 3.38 pmol/L & -0.2 & 0.892 & 1.9 & 0.035 \\
FT3: 3.20-3.38 & -0.6 & 0.477 & 1.0 & 0.183 \\
\hline Abbrevion: FT3 & & & & \\
\hline
\end{tabular}

Abbreviations: FT3 - free triiodothyronine; HPT hypothyroidism; TPO - anti-thyroid peroxidase antibodies; TSH - thyroid stimulating hormone.

that TSH higher than $6.9 \mathrm{mIU} / \mathrm{L}$, particularly for females who have not reached menopause, predicts development of hypothyroidism and worth initiation of therapy. On the other hand, it is recommended to repeat TSH after 6 months for other subjects, particularly males. Women who reached menopause are more likely to stay in the subclinical category particularly if their TSH is equal or below $6.9 \mathrm{mIU} / \mathrm{L}$.

Current trend in clinical practice of repeating TSH after six months to exclude transient hypothyroidism (Abreu et al. 2017) has two adverse consequences. The first is that patients who require treatment for subtle or overt symptoms would be left untreated for 6 months. Based on previous cross-over clinical trial, a good proportion of $\mathrm{SCH}$ patients were aware of response and symptoms upon initiation of treatment (Abu-Helalah et al. 2010). This is due to the subtle and insidious onset of symptoms in the early stages of the disease process (Jameson and Weetman 2001; Wass and Stewart 2011). The second is that early initiation of treatment would prevent further deterioration of thyroid function. Therefore, delays in early intervention would defer such preventive intervention.

Most current recommendations begin initiation of therapy upon diagnosis if the TSH is higher than 10 mIU/L (Premawardhana and Lazarus 2006; Cojic and
Cvejanov-Kezunovic 2017). We are the first published study to provide solid evidence to support immediate initiation of thyroxine replacement therapy for TSH higher than $6.9 \mathrm{mIU} / \mathrm{L}$, particularly for females and those with FT3 and FT4 in the lower half of the reference range. On the other hand, our results support repeating TSH after six months for other subjects, particularly males and those with TSH less than or equal to $6.9 \mathrm{mIU} / \mathrm{L}$. Because symptoms are gradual and insidious in onset, it could be helpful to assess the value of the intervention from patients' prospective is to ask them above symptoms and general assessment of the trial of treatment at baseline and during the follow-up.

Regarding normalization of TSH value and change to the euthyroid status, our findings revealed that SCH patients with higher baseline than FT3 and FT4 were more likely to have their TSH returning to reference range during the follow-up. On the other hand, those with higher TSH (>6.9 mIU/L), older subjects and post-menopausal women are less likely to return to the euthyroid status.

Follow up in our study revealed that the annual incidence of biochemical hypothyroidism amongst subjects with $\mathrm{SCH}$ was of $24.4 \%$. Our findings are close to figures from follow-up of SCH identified through population based general screening in the United Kingdom with rates of $27 \%$ (Fade et al. 1991). These figures are slightly higher than older studies (McGrogan et al. 2008; Wiersinga 1995). Parle et al. (2010) followed 73 patients $\geq 60$ years of age who had been classified with SCH (single TSH value $>5.0 \mathrm{mIU} / \mathrm{L}$ with normal thyroxine) in a singlefamily practice. After follow-up for one year, TSH levels returned to normal in only $5.5 \%$ of these individuals; $76.7 \%$ of the patients had persistent $\mathrm{SCH}$ and $17.8 \%$ progressed to overt hypothyroidism (Fade et al. 1991). A difference in the age range might justify these findings.

Subjects with positive TPO are more likely to develop biochemical hypothyroidism, as shown in most previous studies (McGrogan et al. 2008; Wiersinga 1995), and require initiation of thyroxine replacement therapy (Cojic and Cvejanov-Kezunovic 2017; Abu-Helalah et al. 2010). A smaller number of patients with positive TPO would have acute or subacute thyroiditis (Akamizu and Amino 2017). These subjects are expected to become euthyroid during follow-up; which will require cessation of therapy. These findings are consistent with previous studies and recommendations for initiation of therapy for subjects with positive antibodies (Cojic and Cvejanov-Kezunovic 2017; Abu-Helalah et al. 2010). 
The reported annual incidence of hypothyroidism was $35.7 \%$ for SCH with TSH $>10 \mathrm{mIU} / \mathrm{L}$ and antithyroid antibodies (McGrogan et al. 2008).

A recent systematic review on the natural course of SCH (TSH 4.5-19.9 mIU/L with normal thyroxine) showed consistent findings with our results. Of the 369 patients with available data after 2 years, 35\% reverted to euthyroid status. The frequency of normalization was associated with the degree of baseline TSH level elevations, with reversion to a euthyroid state more common among patients with a baseline TSH 4.5-6.9 mIU/L (46\%) compared with those with a baseline TSH $\geq 7 \mathrm{mIU} / \mathrm{L}$ (8.8\%). Patients that tested negative for TPOAbs were also significantly more likely to revert to euthyroidism compared with those that tested positive for TPOAbs ( $48 \%$ vs. $15 \%, \mathrm{p}<0.05$ ) (Hennessey and Espaillat 2015).

Males are unlikely to develop biochemical hypothyroidism but also less likely to have their TSH returning to the reference range. This means that a follow-up of these subjects on an annual basis would be recommended in addition to consulting them on symptoms suggestive of development of overt hypothyroidism. The 20-year follow-up of the Wickham cohort study provided incidence data and allowed the determination of risk factors for spontaneous hypothyroidism in this period. The mean annual incidence of spontaneous hypothyroidism during the 20-year follow-up period was 3.5 per 1000 and 0.6 per 1000 in surviving women and men respectively (McGrogan et al. 2008).

Our results found that TSH above $6.9 \mathrm{mIU} / \mathrm{L}$ necessitates initiation of therapy. Setting an upper limit for the normal value of TSH for a population has implications for the diagnosis of $\mathrm{SCH}$ as well as related issues such as screening, association with comorbidities, especially cardiovascular risks, and treatment (Baumgartner et al. 2017; Mullur et al. 2014). Thus, the current data support the view that serum TSH rises slightly with aging, but the data on FT4 is conflicting (Baumgartner et al. 2017; Mullur et al. 2014; Bremner et al. 2012). Prospective large studies are required to confirm whether age-specific reference ranges should be utilized when reporting thyroid parameters. In a subsequent further analysis, Surks and Hollowell (2007) examined the NHANESIII data, which showed a progressive increase in mean, median, and 97.5 percentile for TSH concentration with age in the disease-free and reference populations. This analysis suggested that the 97.5 percentile is about $3.6 \mathrm{mIU} / \mathrm{L}$ in people who are $20-39$ years of age and 5.9 and $7.5 \mathrm{mIU} / \mathrm{L}$ in those who are $70-79$ and 80 years old and older, respectively (Surks and Hollowell
2007). They also demonstrated that about $70 \%$ of older patients who would be classified as $\mathrm{SCH}$ with TSH greater than $4.5 \mathrm{mIU} / \mathrm{L}$ were within their agespecific reference range. Consequently, the authors have suggested that age-based reference ranges for TSH should be considered (Bremner et al. 2012).

Moreover, a recent longitudinal study from Western Australia (Busselton survey), for the first time, showed that serum TSH increases (mean increase of $0.32 \mathrm{mIU} / \mathrm{L}$ over 13 years) with no significant change in FT4 concentrations with aging (Bremner et al. 2012). Similarly, another longitudinal thyroid function evaluation in a very elderly subgroup (mean age 85 years) of the Cardiovascular Health Study (All Stars Study) found that serum TSH increased by $13 \%$ over an average of 13 years of follow-up associated with a $1.7 \%$ increase in FT4 and a $13 \%$ reduction in total T3 levels (Surks and Hollowell 2007; Waring et al. 2012).

It has been reported that estradiol concentrations increase TSH concentrations by antagonizing the feedback inhibition of TSH synthesis by T3 (Yarwood et al. 1993). This might justify our findings that ex-users of oral contraceptives are more likely to have their TSH returning to reference range during the follow-up.

The effect of reaching menopause on the thyroid hormonal status has some controversies. Some results suggest it is the age factor effect, more than hormonal impact on serum TSH activities among the postmenopausal and older women. TSH levels were lower, when compared to the pre-menopausal women who had increased activities of serum TSH (Hershman et al. 1993; Mariotti et al. 1993; Pearce 2007). These studies have suggested that this type of scenario may be age-related and could have been influenced by the pituitary gland. Several studies reported that the TSH levels did not differ according to menopausal status (Sowers et al. 2003). A recent study from Tehran evaluated the effect of menopause on thyroid function test based on follow-up for six years. Results showed no association of TSH with reproductive hormone concentrations, including estradiol, following adjustment for age, BMI, clinical site and smoking behavior (Amouzegar et al. 2017).

One of the limitations of our study is that we did not conduct baseline ultrasound for participants in this study for research purposes to correlate biochemical tests changes with U/S findings. It might be suggested to utilize baseline ultrasound instead of the biochemical tests in decisions related to initiation of replacement therapy for subclinical hypothyroidism. Studies indicated that ultrasound findings 
did not predict persistence of $\mathrm{SCH}$ as opposed to a spontaneous return to the euthyroid state (Shin et al. 2010). This emphasizes the importance of our results in decisions related to management of $\mathrm{SCH}$ upon diagnosis. Another limitation might be the duration of follow-up of six months rather than for a longer period. Our primary objective was to identify those who would develop biochemical hypothyroidism during the first six months and therefore require immediate replacement instead of repeat TSH.

\section{Conclusions}

In conclusion, our study showed that female participants with TSH above $6.9 \mathrm{mIU} / \mathrm{L}$, particularly those with FT3 and FT4 in the lower half of the reference range, are more likely to develop biochemical hypothyroidism. Therefore, it is recommended to give them a trial of levothyroxine replacement for prevention of further progress of the disease, treatment of subtle or overt hypothyroidism symptoms, and normalization of their cardiovascular disease risk such as lipid profile. It is also recommended to repeat TSH after six months for male subjects and participants with baseline TSH equal or less than 6.9 $\mathrm{mIU} / \mathrm{L}$. Presence of TPO positivity is very important independent predictor of development of hypothyroidism, however, patients could have a temporary positivity due to transient thyroiditis. Therefore, TSH above $6.9 \mathrm{mU} / \mathrm{L}$ remains the most important factor for prediction of the disease progression from all studied variables.

\section{Acknowledgment}

This research was supported through scientific grant from Mutah University. We, therefore, thank the President Office, Faculty of Medicine, deanship for research for their great administrative support for the project. We also thank the Directorates of Health in Amman, Irbid and Karak for their support and cooperation in the conduct of this project.

\section{References}

Abreu IM, Lau E, de Sousa Pinto B, Carvalho D. Subclinical hypothyroidism: to treat or not to treat, that is the question! A systematic review with meta-analysis on lipid profile. Endocr Connect 6, 188-199, 2017.

Abu-Helalah M, Law M, Bestwick J, Monson J, Wald N. A randomized double-blind crossover trial to investigate the efficacy of screening for adult hypothyroidism. J Med Screen 17, 164-169, 2010.

Abu-Helalah M, Alshraideh HA, Al-Sarayreh SA, Al Shawabkeh AHK, Nesheiwat A, Younes N, Al-Hader A. A crosssectional study to assess the prevalence of adult thyroid dysfunction disorders in Jordan. Thyroid 29, 10521059, 2019.

Akamizu T, Amino N. Hashimoto's Thyroiditis. In: Feingold KR, Anawalt B, Boyce A, Chrousos G, de Herder WW, Dhatariya K, Dungan K, Grossman A, Hershman JM, Hofland J, Kalra S, Kaltsas G, Koch C, Kopp P, Korbonits M, Kovacs CS, Kuohung W, Laferrere B, McGee EA, McLachlan R, Morley JE, New M, Purnell J, Sahay R, Singer F, Stratakis CA, Trence DL, Wilson DP, editors. Endotext [Internet]. South Dartmouth (MA): MDText.com, Inc.; 2000-, 2017.

Amouzegar A, Ghaemmaghami Z, Beigy M, Gharibzadeh S, Mehran L, Tohidi M, Azizi F. Natural course of euthyroidism and clues for early diagnosis of thyroid dysfunction: Tehran thyroid study. Thyroid 27, 616-625, 2017.

Baumgartner C, da Costa BR, Collet TH, Feller M, Floriani C, Bauer DC, Cappola AR, Heckbert SR, Ceresini G, Gussekloo J, den Elzen WPJ, Peeters RP, Luben R, Volzke H, Dorr M, Walsh JP, Bremner A, Iacoviello M, Macfarlane P, Heeringa J, Stott DJ, Westendorp RGJ, Khaw KT, Magnani JW, Aujesky D, Rodondi N; Thyroid Studies Collaboration. Thyroid function within the normal range, subclinical hypothyroidism, and the risk of atrial fibrillation. Circulation 136, 2100-2116, 2017.

Bremner AP, Feddema P, Leedman PJ, Brown SJ, Beilby JP, Lim EM, Wilson SG, O’Leary PC, Walsh JP. Age-related changes in thyroid function: a longitudinal study of a community-based cohort. J Clin Endocrinol Metab 97, 1554-1562, 2012.

Canaris GJ, Manowitz NR, Mayor G, Ridgway EC. The Colorado thyroid disease prevalence study. Arch Intern Med $160,526-534,2000$.

Cojic M, Cvejanov-Kezunovic L. Subclinical hypothyroidism - whether and when to start treatment? Open Access Maced J Med Sci 5, 1042-1046, 2017.

Dimos G, Pappas G, Akritidis N. Subacute thyroiditis in the course of novel H1N1 influenza infection. Endocrine 37, 440-441, 2010. 
Fade J, Franklyn J, Cross K, Jones S, Sheppard M. Prevalence and follow-up of abnormal thyrotrophin (TSH) concentrations in the elderly in the United Kingdom. Clin Endocrinol (Oxf) 34, 77-84, 1991.

Garber JR, Cobin RH, Gharib H, Hennessey JV, Klein I, Mechanick JI, Pessah-Pollack R, Singer PA, Woeber KA; American Association Of Clinical Endocrinologists And American Thyroid Association Taskforce On Hypothyroidism In Adults. Clinical practice guidelines for hypothyroidism in adults: cosponsored by the American Association of Clinical Endocrinologists and the American Thyroid Association. Thyroid 22, 1200-1235, 2012.

Hennessey J, Espaillat R. Subclinical hypothyroidism: a historical view and shifting prevalence. Int J Clin Pract 69, 771-782, 2015.

Hershman JM, Pekary AE, Berg L, Solomon DH, Sawin CT. Serum thyrotropin and thyroid hormone levels in elderly and middle-aged euthyroid persons. J Am Geriatr Soc 41, 823-828, 1993.

Huber G, Staub JJ, Meier C, Mitrache C, Guglielmetti M, Huber P, Braverman LE. Prospective study of the spontaneous course of subclinical hypothyroidism: prognostic value of thyrotropin, thyroid reserve, and thyroid antibodies. J Clin Endocrinol Metab 87, 3221-3226, 2002.

Jameson JL, Weetman AP. Diseases of the thyroid, in Harrison's Principles of Internal Medicine, 15th ed. (Ed. Braunwald E.), McGraw-Hill, New York, pp. 2060-2084, 2001.

Jonklaas J, Bianco AC, Bauer AJ, Burman KD, Cappola AR, Celi FS, Cooper DS, Kim BW, Peeters RP, Rosenthal MS, Sawka AM; American Thyroid Association Task Force on Thyroid Hormone Replacement. Guidelines for the treatment of hypothyroidism: prepared by the american thyroid association task force on thyroid hormone replacement. Thyroid 24, 1670-1751, 2014.

Khandelwal D, Tandon N. Overt and subclinical hypothyroidism. Drugs 72, 17-33, 2012.

Kish L. Survey Sampling. John Wiley \& Sons, Inc., New York, London 1965.

Lee MW, Lee EJ. Response: the biochemical prognostic factors of subclinical hypothyroidism (Myung Won Lee et al. Endocrinol Metab 29, 154-162, 2014). Endocrinol Metab (Seoul) 29, 402-403, 2014.

Mariotti S, Barbesino G, Caturegli P, Bartalena L, Sansoni P, Fagnoni F, Monti D, Fagiolo U, Franceschi C, Pinchera A. Complex alteration of thyroid function in healthy centenarians. J Clin Endocrinol Metab 77, 1130-1134, 1993.

McGrogan A, Seaman HE, Wright JW, De Vries CS. The incidence of autoimmune thyroid disease: a systematic review of the literature. Clin Endocrinol (Oxf) 69, 687-696, 2008.

Mullur R, Liu YY, Brent GA. Thyroid hormone regulation of metabolism. Physiol Rev 94, 355-382, 2014.

Ohsako N, Tamai H, Sudo T, Mukuta T, Tanaka H, Kuma K, Kimura A, Sasazuki T. Clinical characteristics of subacute thyroiditis classified according to human leukocyte antigen typing. J Clin Endocrinol Metab 80, 36533656, 1995.

Parle J, Roberts L, Wilson S, Pattison H, Roalfe A, Haque MS, Heath C, Sheppard M, Franklyn J, Hobbs FD. A randomized controlled trial of the effect of thyroxine replacement on cognitive function in community-living elderly subjects with subclinical hypothyroidism: the Birmingham Elderly Thyroid study. J Clin Endocrinol Metab 95, 3623-3632. 2010.

Pearce EN. Thyroid dysfunction in perimenopausal and postmenopausal women. Menopause Int 13, 8-13, 2007.

Premawardhana L, Lazarus J. Management of thyroid disorders. Postgrad Med J 82, 552-558, 2006.

Redford C, Vaidya B. Subclinical hypothyroidism: Should we treat? Post Reprod Health 23, 55-62, 2017.

Shin DY, Kim EK, Lee EJ. Role of ultrasonography in outcome prediction in subclinical hypothyroid patients treated with levothyroxine. Endocr J 57, 15-22, 2010.

Sowers M, Luborsky J, Perdue C, Araujo KL, Goldman MB, Harlow SD; SWAN. Thyroid stimulating hormone (TSH) concentrations and menopausal status in women at the mid-life: SWAN. Clin Endocrinol (Oxf) 58, 340-347, 2003.

Surks MI, Hollowell JG. Age-specific distribution of serum thyrotropin and antithyroid antibodies in the US population: implications for the prevalence of subclinical hypothyroidism. J Clin Endocrinol Metab 92, 4575-4582, 2007.

Tunbridge WM, Brewis M, French JM, Appleton D, Bird T, Clark F, Evered DC, Evans JG, Hall R, Smith P, Stephenson J, Young E. Natural history of autoimmune thyroiditis. Br Med J (Clin Res Ed) 282, 258-262, 1981.

Vanderpump MP, Tunbridge WM, French JM, Appleton D, Bates D, Clark F, Grimley Evans J, Hasan DM, Rodgers $\mathrm{H}$, Tunbridge F, et al. The incidence of thyroid disorders in the community: a twenty-year follow-up of the Whickham Survey. Clin Endocrinol (Oxf) 43, 55-68, 1995.

Vanderpump MP, Tunbridge WMG. Epidemiology and prevention of clinical and subclinical hypothyroidism. Thyroid 12, 839-847, 2002. 
Waring AC, Arnold AM, Newman AB, Buzkova P, Hirsch C, Cappola AR. Longitudinal changes in thyroid function in the oldest old and survival: the cardiovascular health study all-stars study. J Clin Endocrinol Metab 97, 3944-3950, 2012.

Wass JAH, Stewart PM. Oxford Textbook of Endocrinology and Diabetes, Oxford University Press, New York, 2011. Wiersinga WM. Subclinical hypothyroidism and hyperthyroidism. I. Prevalence and Akaclinical relevance. Neth J Med 46, 197-204, 1995.

Wilson S, Parle JV, Roberts LM, Roalfe AK, Hobbs FD, Clark P, Sheppard MC, Gammage MD, Pattison HM, Franklyn JA; Birmingham Elderly Thyroid Study Team. Prevalence of subclinical thyroid dysfunction and its relation to socioeconomic deprivation in the elderly: a community-based cross-sectional survey. J Clin Endocrinol Metab 91, 4809-4816, 2006.

Yarwood NJ, Gurr J, Sheppard MC, Franklyn J. Estradiol modulates thyroid hormone regulation of the human glycoprotein hormone alpha subunit gene. J Biol Chem 268, 21984-21989, 1993. 